\title{
MUSICOTERAPIA INSTITUCIONAL NA SAÚDE DO TRABALHADOR: CONEXÕES, INTERFACES E PRODUÇÕES
}

\author{
Laize Guazina \\ Faculdade de Artes do Paraná, Curitiba, Brasil \\ Jaqueline Tittoni \\ Universidade Federal do Rio Grande do Sul, Porto Alegre, Brasil
}

\begin{abstract}
RESUMO: Este trabalho propõe e analisa a Musicoterapia como estratégia de produção de saúde do trabalhador, em estudo desenvolvido junto a profissionais técnicas de enfermagem de uma Unidade de Terapia Intensiva infantil de um hospital público da cidade de Porto Alegre. A atenção à saúde dos trabalhadores produz novas questões teórico-conceituais, práticas, éticas e políticas no campo da Musicoterapia, ligadas ao território do trabalho e suas configurações contemporâneas, ao "ser" trabalhador e à saúde, e que têm implicações sobre a Musicoterapia e o musicoterapeuta na contemporaneidade. À luz das contribuições de Foucault, este trabalho centraliza-se na discussão do hospital como território de produção de subjetividades, a partir do desenvolvimento do conceito de 'Panáudio', mapeando e analisando efeitos deste dispositivo, que se efetivam pelos contextos sonoros. Aponta controles e resistências possíveis e propõe a produção de novas subjetividades pelo uso das práticas musicais em Musicoterapia em uma proposta de abordagem institucional.
\end{abstract}

PALAVRAS-CHAVE: musicoterapia institucional; modos de subjetivação; saúde do trabalhador; Panáudio; práticas musicais

\section{INSTITUTIONAL MUSIC THERAPY IN WORKERS' HEALTH: CONNECTIONS, INTERFACES AND PRODUCTION}

\begin{abstract}
This paper proposes and analyzes Music Therapy as a production strategy towards workers' health in a study developed with nurse technicians from a Children's Intensive Care Center of a public hospital in Porto Alegre. The concern with workers' health brings about new theoretical, conceptual, ethical and political queries in the field of Music Therapy, such queries are related with the working field and its contemporary features, with the working being and with health; these queries produce consequences on Music Therapy and Music therapists contemporarily. Based on Foucault's contributions, this paper focuses on the discussion about hospitals being a field for subjectivities production, from the development of the 'Panaudio' concept, mapping and analyzing its effects, which are effective by sound contexts. This paper also points out possible controls and resistances and proposes the production of new subjectivities by using musical practices in Music Therapy, in a proposal of institutional approach.
\end{abstract}

KEYWORDS: institutional music therapy; ways of subjectivation; workers' health; Panaudio; musical practices.

\section{Introdução}

Este artigo origina-se da dissertação de mestrado "Sons, Silenciamentos, Poder e Subjetivação no Hospital: a Musicoterapia na saúde do trabalhador" desenvolvida no Programa de Pós-graduação em Psicologia Social e Institucional da Universidade Federal do Rio Grande do Sul (UFRGS), em que foram analisadas as contribuições da Musicoterapia na intervenção em Saúde do Trabalhador em um hospital público da cidade de Porto Alegre. Para este estudo, durante o ano de 2005, foram realizadas diferentes intervenções de modo a produzir espaços de reflexão sobre os contextos sono- ros e seus efeitos na saúde das profissionais técnicas de enfermagem que trabalhavam em uma unidade de Terapia Intensiva infantil. Foi realizada, inicialmente, uma série de observações do trabalho e dos modos de trabalhar das profissionais técnicas de enfermagem, e foram propostas oficinas de Musicoterapia em que, por meio de experiências musicais ${ }^{1}$ em Musicoterapia, foram focalizados saúde e trabalho. Essas oficinas mostraram os primeiros elementos articuladores de nossas análises, sobretudo, ao indicar os sentidos de estranhamento provocados com a introdução da música no hospital e, também, ao revelarem o hospital como um local bastante ruidoso e, mais ainda, onde o ruído 
é uma forma de controlar os movimentos oscilatórios que convocam à vida e à morte e acabam por constituirse em importantes estratégias para controlar a própria atividade dessas trabalhadoras. As oficinas indicaram outras estratégias, como o acompanhamento mais próximo do cotidiano de trabalho, que levou à proposição de algumas intervenções de música na unidade, onde as trabalhadoras poderiam escolher as músicas que gostariam de ouvir enquanto trabalhavam.

As reflexões apresentadas neste texto orientamse para a construção da categoria "panaúdio", que se construiu no contexto deste estudo por meio da análise do trabalho como território de jogos de verdade e de relações de poder e produtor de modos de subjetivação, baseados no pensamento foucaultiano. Também na noção de saúde de Canguilhem (2002), em que a possibilidade de ser normativo é uma expressão da saúde, e na noção de música construída numa interlocução entre autores da área (Araújo, 1992-1993; Napolitano, 2002; Schafer, 1991; Tragtenberg, 1999) e os estudos foucaultianos, onde a música pode funcionar como um elemento modificador e mesmo transgressor do contexto legitimado de silêncio, do ruído, da hierarquia e da rigidez do trabalho hospitalar. Essas conexões teóricoconceituais permitiram tensionar os campos delimitados da saúde, do trabalho e da música, aproximando e conectando as disciplinas da Saúde do Trabalhador e da Musicoterapia.

\section{Sobre Saúde do Trabalhador, Subjetividade e Musicoterapia: Encontros}

A Saúde do Trabalhador é um campo de conhecimento que envolve diferentes disciplinas e que propõe intervenções nos locais de trabalho, orientadas para a vigilância e a transformação das condições e contextos laborais considerados nocivos à saúde dos trabalhadores (Dias, 1994; Nardi, 1999). Esse campo emergiu no Brasil em um processo de luta pela abertura política, durante a década de 80 , e sua produção se deu no contexto do Sistema Único de Saúde. Caracteriza-se por conceber o trabalhador como sujeito conhecedor de seu trabalho e ativo no processo saúde-doença, entendido como multicausal, bem como entende que as experiências dos trabalhadores no seu cotidiano de trabalho podem ser estratégias para problematização das possibilidades de saúde-adoecimento no trabalho, objetivando produzir diferentes práticas de atenção à saúde dos trabalhadores (Nardi, 1999).

Dentre as possibilidades de reflexão sobre a Saúde do Trabalhador, destacamos aquelas ligadas às contribuições de Canguilhem (2002) quando analisadas desde a concepção de saúde propostas pelo autor.
Pautado na problematização dos conceitos de normal/ anormal e saúde/doença, o autor define que a "doença não é uma variação da dimensão da saúde; ela é uma nova dimensão da vida" (p. 149) e ser normal é a possibilidade de ser normativo em diferentes situações. Assim, ser saudável é ser capaz de sobrepor-se à norma que define a normalidade em um momento, instituindo novas normas para novas situações.

Para Nardi, Tittoni e Bernardes (2002, p. 304), pensar a subjetividade e o trabalho implica pensar como os modos de trabalhar e as experiências no trabalho "conformam modos de agir, pensar, sentir e trabalhar amarrados em dados momentos - mais ou menos duráveis - que evocam a conexão entre diferentes elementos, valores, necessidades e projetos". Tais elementos estão imbricados com a vida "fora" do trabalho e são visibilizados pela análise do cotidiano. Esses caminhos levam à conformação, também, de diferentes possibilidades de invenção e criação de múltiplos modos de trabalhar, "na forma de transgressões ou mesmo de resistências e potências na conexão dos diversos elementos e dos modos de produzir e trabalhar" (Nardi et al., 2002, p. 304). Nesse contexto, a produção de saúde pode ser construída a partir do reconhecimento das experiências dos trabalhadores como conhecedores do seu trabalho e como sujeitos capazes de produzir novas alternativas de vida frente às situações potencialmente nocivas de trabalho.

A subjetividade, segundo Foucault (1999, p.365), é definida como "a maneira pela qual o sujeito faz a experiência de si mesmo em um jogo de verdade que tem relação consigo", enquanto os jogos de verdade podem ser compreendidos como as regras que definem o que será considerado verdadeiro ou falso em cada tempo e espaço. Isto é o que o autor define como "regime de verdade", ou "política de verdade" de cada sociedade. Nesses regimes, alguns discursos se legitimam e se consolidam, ordenando os modos de ser e viver, nos seus diversos âmbitos (Foucault, 2003a, 2003b). Para estar no território daquilo que é verdadeiro é necessário dizer aquilo que é tomado como verdade em um dado momento e contexto.

O poder é compreendido na forma das relações de poder, que são um modo de ação sobre a ação de outros, numa relação entre indivíduos ou grupos, onde uns exercem poder sobre outros, uma vez que exercem ação sobre a ação dos outros - em ato. As relações de poder somente podem ser exercidas quando entre "sujeitos livres" e ativos - "sujeitos individuais ou coletivos que têm diante de si um campo de possibilidade onde diversas condutas, diversas reações e diversos modos de comportamento podem acontecer" (Foucault, 1995a, p. 244). Os sujeitos podem produzir resistências, assim como produzir práticas de liberdade ${ }^{2}$, por meio da busca de novas possibilidades de existência e uma 
nova relação consigo que, em última análise, produzem novas formas de viver (Nardi, 2003). A possibilidade de construção de si mesmo e da própria vida, uma vez que não são dadas, têm, para Foucault (1995b, p. 262), uma consequência prática: "temos que nos criar a nós mesmos como uma obra de arte", inspirando-se na ideia de que a ética é suporte de existência e nas construções renascentistas de Burkhardt sobre uma estética da existência - o herói como sua própria obra de arte.

A partir dessas construções foucaultianas, buscamos um percurso que produza encontros entre as noções de saúde e subjetividade com as noções de música e de Musicoterapia.

A Musicoterapia é um campo de conhecimento e profissional de formação de terceiro grau específica, que tem como característica principal o uso da música para a saúde das pessoas com base nas experiências musicais. Esse é um campo complexo e multifacetado, com diferentes linhas teóricas e áreas de aplicação que se desenvolve na interlocução com diferentes campos de produção e conhecimento em saúde.

A relação entre práticas musicais e práticas de saúde é tão antiga quanto a própria humanidade, porém, os regimes de verdade que sustentam esta disciplina e a situam dentro da Ciência apenas se constroem no século XX, a partir da II Guerra Mundial, sobretudo em experiências com feridos de guerra em hospitais (Costa, 1989; Gaston, 1968).

A análise de vários estudos (Costa, 1989; Lapoujade \& Lecourt, 1996; Pailles \& Caladou citados por Chagas, 2001a, entre outros) evidencia a associação dos saberes e práticas de utilização da música para a saúde com práticas médicas, na constituição do campo que veio se tornar a Musicoterapia, sobretudo, a partir do séc. XX. Dessa análise pode-se inferir sobre como esse campo pode ter sido construído enlaçado com as demandas de adaptabilidade dos pacientes e com a normatização do discurso médico sobre a loucura.

Um levantamento bibliográfico realizado em 2004 a respeito da produção intelectual dos musicoterapeutas brasileiros, enfocando atividades diretas com trabalhadores, constatou um número significativo de trabalhos voltados à redução do estresse, em geral ligados à área de Recursos Humanos, e em duas linhas principais: ou associados à "Musicoterapia Organizacional", ou associados aos estudos sobre subjetividade e trabalho. Na primeira linha, foram encontradas ofertas de trabalho ligadas às possibilidades de "melhora na qualidade de vida para maior produtividade", o que leva a questionamentos sobre a falta de posicionamento crítico frente às implicações desta intervenção profissional para o trabalhador, assim como as funções que a Musicoterapia e o musicoterapeuta exercem nesta prática $^{3}$. Dessa forma, cabe perguntarmo-nos: quais as possibilidades e implicações da música, da Musicoterapia e do próprio musicoterapeuta na produção da saúde do trabalhador?

Tomando a música como referência, temos em Napolitano (2002, p. 32) que nela estão presentes "posições sociológicas, contradições políticas, econômicas, ideológicas e culturais que perpassam uma sociedade" e, segundo Chanan (1999, citado por Napolitano, 2002, p. 94),

“'subjetividade' e 'esfera pública' não se autoexcluem e, na experiência musical, se

construíram mutuamente". Para Wisnik (2001, p. 13),

a música fala ao mesmo tempo ao horizonte da sociedade e ao vértice subjetivo de cada um, sem se deixar reduzir às outras linguagens.... A música ensaia e antecipa aquelas transformações que estão se dando, que vão se dar, ou que deveriam se dar, na sociedade.

Deste modo, propomos uma flexão na própria noção de música, compreendendo-a como práticas musicais. As práticas musicais são um conceito que problematiza a naturalização do conceito de música como algo dado e que seria compreendido como algo único em todas as sociedades. Conforme Araújo (1992-1993), as práticas musicais podem ser compreendidas como as diferentes formas pelas quais os seres humanos organizam o exercício do trabalho acústico. Essas diferentes formas de trabalhar o material acústico - que na nossa sociedade denominamos "música" - precisam necessariamente ser contextualizadas dentro do campo de forças de cada sociedade ou grupo humano, uma vez que as formas de exercer essas práticas, seus sentidos e implicações são diferentes e se inter-relacionam com as diferentes esferas da vida de uma sociedade e de cada indivíduo, conjuntamente.

A partir dessas concepções e em relação com a teoria foucaultiana, compreendemos as práticas musicais como uma produção social e histórica que carrega marcas espaço-temporais, e que podem ser um contexto, território ou produto sonoro operado, situado e validado a partir de certas discursividades que definem suas características estéticas. Essas discursividades possibilitam que diferentes jogos de verdade operem na vida cotidiana, para a produção de diferentes efeitos de poder. Efeitos estes que podem produzir criação, libertação, mas também normatização, delimitação, entre outros, em possibilidades que vão muito além dos binarismos. As relações de poder e seus efeitos são fluxos de força nos modos de subjetivação, e as práticas musicais integram-se nesses fluxos, também existindo em exercício. Da mesma forma, as práticas e saberes musicais estão ligados às maneiras pelas quais os sujeitos se relacionam consigo, se reconhecem como 
objeto de um saber possível e reforçam, transgridem ou modificam as práticas divisórias ${ }^{4}$. Portanto, participam ativamente de como, em nossas sociedades, o sujeito se torna e se reconhece como sujeito.

As vivências e experiências com música respondem às regras da moral e a outras regras, conectadas entre si (tal como as regras técnicas de estilo). Os sujeitos produzem "música", mantendo, da mesma maneira, a negociação com essas regras, que são produzidas, reproduzidas, transgredidas, enfim, tratando dos diferentes âmbitos da vida. Essas práticas veiculam discursividades da mesma forma com que veiculam o discurso musical, intrincado com suas próprias características. Também podem fazer surgir efeitos de poder não esperados, em movimentos diruptivos e libertários, ou mesmo mascarar a manutenção das sujeições, na forma de liberdades aparentes.

A partir do arcabouço referencial aqui proposto, pensar a Musicoterapia também se torna objeto de deslocamentos das concepções mais hegemônicas da área.

A Musicoterapia Institucional deriva dessas flexões e propõe denominar-se assim devido às suas bases foucaultianas na compreensão e ação sobre as instituições em que se produz, bem como das práticas musicais. Compreende as possibilidades teórico-conceituais e práticas da Musicoterapia, nesta abordagem, como necessariamente imbricadas com as capilaridades de poder na construção do sujeito, da instituição, da música, da saúde e do trabalho. Sendo assim, compreende os potenciais da própria área no território do trabalho - e no próprio campo social - interligados à produção de deslocamentos das cristalizações dos lugares e dos reconhecimentos de si, a partir da intervenção musicoterápica nas relações de poder. Intervenções que podem agenciar a produção de outros lugares e reconhecimentos de si, através da busca das novas práticas de liberdade e transgressão frente às relações de dominação potencialmente causadoras de sofrimento e adoecimento, pela via do uso das práticas musicais em Musicoterapia. Esta concepção apoia-se na concepção de práticas musicais à luz das contribuições foucaultianas, como explicitado antes, e opera a partir do mapeamento e reconhecimento dos tensionamentos ligados aos contextos sonoros do trabalho e de como estes se interligam com os modos de subjetivação, daí que preconiza, necessariamente, o mapeamento sonoro dos contextos de trabalho e suas relações com diferentes âmbitos de cada atividade e instituição, tanto na organização do trabalho quanto das condições de trabalho, bem como outros âmbitos que possam se mostrar importantes. Assim, uma das principais intervenções musicoterápicas é a Audição Musical, seguida por outras intervenções musicoterápicas que forem necessárias, segundo os contextos laborais encontrados. Apoia-se também nas concepções da Saúde do Trabalhador e no contexto político desse campo.

\section{O Trabalho Hospitalar: A Paisagem Sonora de uma UTI Infantil e o Panáudio}

A partir das contribuições de Castel (1998, p. 24), compreendemos que "o trabalho não é apenas uma relação técnica de produção, mas um suporte privilegiado de inscrição na estrutura social". Entretanto, a precarização do trabalho, com a progressiva perda das proteções sociais e direitos dos trabalhadores, tem tornado esses laços cada vez mais frágeis. Neste mesmo panorama inclui-se o modelo da competência (Durand, 2003) no qual se expressam o fluxo tensionado - tensão que mediatiza o fluxo produzido - e os controles morais sobre os trabalhadores, os quais tornam aceitáveis até as condições mais difíceis de trabalho na luta pela sobrevivência.

No contexto hospitalar, os controles são parte importante e característica do trabalho. Tal como descrito por Osório da Silva (2002), o trabalho em um grande hospital brasileiro (hospital-escola, neste estudo) é caracterizado por uma rígida e coercitiva hierarquia, sobretudo no grupo de enfermagem, da qual pertencem as profissionais técnicas em enfermagem ${ }^{5}$. A hierarquia define significativamente as relações, a organização do espaço, a multiplicidade de chefias organizadas por profissão e especialidade, além do ocultamento seletivo das informações em todos os âmbitos e do uso da linguagem cifrada por todas as categorias de trabalhadores.

Além disso, a enfermagem hospitalar enfrenta reconhecidos agressores ligados à vida laboral ${ }^{6}$, ao cuidado (Pitta, 1999), à invisibilidade de gênero em uma categoria eminentemente feminina (Lopes \& Leal, 2005).

Pensar o contexto sonoro de um hospital e de uma Unidade de Terapia Intensiva infantil, inicialmente, pode levar à conclusão de que esses são lugares de muito silêncio. Entretanto, a paisagem sonora ${ }^{7}$ da UTI infantil estudada caracterizava-se, à época do estudo, por um conjunto de sons composto por conversas, choros, sons decorrentes do movimento de pessoas, televisão, equipamentos, e pela presença marcante dos sons das máquinas (responsáveis por traduzir os sinais vitais do paciente, assim como sinalizam outras funções), os quais eram constantemente denominados pelas trabalhadoras como "barulho". Esse grande conjunto de sons formava um ruído constante, onde por vezes se distinguiam um ou outro dos elementos, entre os muitos barulhos da aparelhagem. As máquinas estavam permanentemente ligadas, e a grande maioria delas permanecia sobre a cabeceira dos pacientes sinalizando sonoramente de maneira ininterrupta, a qualquer 
hora. O ruído, por si só, não é um elemento negativo ou positivo. São os contextos espaço-temporais que determinam sua importância ${ }^{8}$.

Esses barulhos costumavam ser a primeira referência que as técnicas em enfermagem faziam sobre o contexto sonoro de seu trabalho, acompanhado de comentários acerca do incômodo que estes mesmos barulhos provocavam: eram "estressantes", "desagradáveis", "irritantes" e "cansativos", apesar de necessários ao trabalho. Já os sons das pessoas só foram citados em situações em que eram tomados como um sinal negativo de comportamento (falar "alto demais"), ou em situações em que se tornavam diruptivos, como o choro.

Entretanto, alguns contextos do hospital, desde uma perspectiva musical e musicoterápica, revelam outras características importantes, bem como se revelam como produções de origem institucional entrelaçadas com as relações de poder.

A análise de Foucault (1975) acerca do Panóptico de Bentham inspirou-nos na análise de algumas formas de controle encontradas no hospital contemporâneo. Foucault encontrou na arquitetura de Bentham elementos presentes no disciplinamento do corpo e na coerção, por meio da vigilância e inspeção, que se realiza através do olhar contínuo. Mantém-se, assim, o poder em funcionamento. Por meio do dispositivo panóptico, o autor analisa as estratégias de controle que fazem funcionar "relações de poder numa função, e uma função para essas relações de poder" (Foucault, 1975, p.182). Em tempos de sociedade de controle (Deleuze, 1992), os moldes disciplinares dos grandes confinamentos foram paulatinamente substituídos por modulações de controle rápidas, contínuas, ilimitadas e móveis de uma moldagem autodeformante. O controle não está fora, mas dentro, onipresente e onisciente.

Desde o início do trabalho de campo desta pesquisa, quando da realização de algumas oficinas preliminares utilizando ferramentas de intervenção da Musicoterapia ${ }^{9}$, chamou nossa atenção o fato de que muitas das profissionais técnicas em enfermagem faziam referência à dificuldade ou impossibilidade da sua "voz sair", ou de ter que falar "baixo", ou mesmo não poder falar, a não ser sobre aquilo que é lícito falar, ou ainda, falar sem terminar as frases ou palavras, dando a entender o sentido e o conteúdo (falar "não falando"). Conjuntamente, havia referência constante a "não saber" ou "não lembrar" as músicas, mesmo que, na prática, as soubessem. Havia um excesso de barulhos das aparelhagens, que funcionavam para a manutenção da vida dos pacientes, mas também como meio de controle hierárquico sobre as técnicas em enfermagem ("aqueles que mandam, mas não ficam para ouvir"). A isto estava ligado um certo "afogamento" da vida nas contingências de som dessa unidade - não fazer mais sons num ambiente de tanto ruído.
Também ocorriam constantes declarações, por parte da chefia da unidade em questão, de que era permitido utilizar música dentro da UTI infantil, apesar de várias constatações contrárias a isso. Somavam-se, também, as discursividades dominantes de que, caso houvesse música na unidade, deveria ser "lenta-clássica-instrumental-calma-relaxante", numa associação naturalizada entre "música lenta-calma" e "música clássica-validação-boa música" e desta em oposição ao "não saber" das técnicas em enfermagem. Ainda havia a associação entre a música e as discursividades ligadas ao prazer e ao entretenimento, onde a música era tomada como oposta ao trabalho, resultando numa associação com a "vagabundagem". A música também era tomada como oposta a um ambiente em que há a presença da morte e em um local associado à Saúde e à Ciência - em oposição à Arte. Leveza ou fruição não seriam possibilidades razoáveis para a moral do trabalho dessa UTI. Também sentimos e compreendemos as impossibilidades em realizar intervenções que necessitassem de sigilo, pois a estrutura do hospital se configurava como um lugar em que tudo podia ser ouvido, ainda que não pudesse ser visto, pois se ouvia do lado de fora o que era dito nas salas.

Com base nas relações produzidas no campo e nas análises de Foucault sobre o Panóptico, formulamos o conceito de Panáudio como um dispositivo de controle produzido a partir dos contextos sonoros do hospital, e que se realiza, portanto, através das relações de poder que se viabilizam por esses contextos sonoros, por relações de poder "sonoras", por jogos de audibilidade e inaudibilidade.

O hospital contemporâneo tem um funcionamento com raízes no panoptismo, mas como todo maquinário contemporâneo, desenvolveu controles mais fluidos, mais rápidos e mesmo fugidios, tal como os centrados no ouvir e escutar, que não necessitam ver ou serem vistos para a manutenção dos controles. Atravessa as paredes, junto com os fluxos sonoros, daí que também se utiliza a arquitetura, mas não se restringe a ela. Controle constante, contínuo e permanente na impermanência: o som se dá sempre no tempo, seus efeitos são constantes, mas sua existência física é fugidia e inapreensível tal qual o próprio tempo. Este dispositivo é modulador de modos de existir, viver e trabalhar, a partir de dispositivos que tudo fazem ouvir, pouco permitem escutar, pouco permitem cantar e fazem falar a tudo que é lícito falar - fala-se muito o que deve ser dito ${ }^{10}$. O conceito de sofrimento silenciado desenvolvido por Tittoni (2004) contribui para a compreensão desses efeitos, na medida em que propõe que o silêncio implica tanto as estratégias do "fazer calar" pela autoridade e hegemonia das diferentes discursividades quanto "fazer falar" para controlar o que é dito. 
O Panáudio é um dispositivo de controle que se exerce pelos contextos sonoros, com outras tecnologias e o mesmo fim do Panóptico: manter os fluxos dominantes das relações de poder e controles do hospital, produzir verdades, construir sujeitos e conhecimentos sobre eles, ordená-los, moldá-los e tomar as forças e a produção de seu trabalho. O Panáudio é um agenciador de modos de subjetivação no hospital, produzindo formas de funcionamento das relações de poder que são ágeis e ora seguem numa direção de fluxos, ora noutra, permitindo que, o que agora submete, daqui a pouco possa libertar. Ele parece aprisionar os "sentidos", sejam eles ligados às percepções sensoriais, ou aos sentidos das experiências para aquelas pessoas.

O Panáudio é composto por essas múltiplas discursividades, tecnologias e efeitos que produzem um sujeito trabalhador silenciado num hospital ruidoso. A música pode ser ameaçadora porque desestabiliza o Panáudio e pode abrir espaço e tempo para as práticas de liberdade. Como o Panóptico, atinge um grande coletivo de pessoas, em que todos são inspetores. É um dispositivo que parece ser mais rápido, moldável e sutil que o Panóptico, uma vez que se dá pelos contextos sonoros (o som só existe em ação, no tempo).

O mapeamento dos efeitos e tecnologias do Panáudio foram parte desta pesquisa, e foram encontrados em todas as fases de campo, com diferentes características. Esses efeitos entrecruzavam-se, interpunham-se e se contrapunham sem que se perdessem suas especificidades, numa constante provocação entre sujeição, resistência e liberdades renitentes. Eram a vida e a morte em combate, o som e o silenciamento, em elementos que ora reproduziam os modos de subjetivação dominantes, ora tendiam a movê-los, sem que com isso estivessem em oposição, ou fossem estanques, como explicitados no fragmento de campo descrito abaixo

Constança canta uma canção de Débora Blando, comenta sobre os agudos executados pela cantora e canta:

\footnotetext{
"Vem sentir a era da águas, O velho tempo terminou.

Diz (novamente) que sentada não conseguiria cantar os agudos.

Pesquisadora: Também dá para levantar e...

Constança: Sim, né, pois é...não sei porque [ela não levanta], embora hoje eu esteja mais solta um pouco.... Vou fazer em pé, então, solenemente. Oh... que chique.
Pesquisadora: Solenemente...

Constança: Solenemente. O negócio é que não tem que ser solene, né...

Pesquisadora: Não...

Constança: É, também acho que não. Pode ser bem descontraída.

Pesquisadora: A não ser que tu queiras fazer solenemente.

Constança: Não. Vou fazer a coisa mais leve. Já basta o solene que eu tenho que estar lá de manhã. Ai, hoje eu não sei o que que eu tinha. Tava uma ardência no peito, assim, isso que eu não estava com paciente grave nem nada, né, mas tava no início da manhã tensa. Ai depois passou.... Então hoje vamos relaxar..

Pesquisadora: Vamos. Disso aqui que a gente tem, o que pode te ajudar a relaxar?

Constança: A música é relaxante.

Pesquisadora: Fazer música..

Constança: Fazer música. [risos]

Pesquisadora: E tu achas que dá para fazer mais alguma coisa com música além de relaxar?

Constança: Dá para criar, dá para expressar sentimento, tanto de alegria, tristeza, dor..

Pesquisadora: Como é que é ser técnica em enfermagem?

Constança: [toca o caxixí] Em música?

Pesquisadora: É... se não tiver nenhuma que sirva, podemos montar [compor outra música].

[Constança toca o caxixí enquanto pensa. Experimenta diferentes células rítmicas breves]

Constança: To pensando numa floresta [toca o caxixí em um ritmo acelerado, enquanto fala] cheio de bichos fazendo barulho. [risadas]

Pesquisadora: É assim?! [pesquisadora toca percussão junto].

Constança: Eu acho. Acho que é isso.

Pesquisadora: Como seria essa floresta? Cheia de bichos fazendo barulho...

Constança: [segue tocando o caxixí acompanhando seu raciocínio] É... coruja, [imitamos corujas] prrrrprrprrr...

Pesquisadora: O que mais que tem?

Constança: Grilos [tocamos os instrumentos de percussão com mais intensidade e imitamos grilos e corujas], cricricricricri... ииииии... macaco [acrescentamos sons de macacos]. É cheia de bicho...

Pesquisadora: É cheia de bicho...

Constança: É cheia de bicho... 
Constança [enquanto tocamos]: Uma cachoeira lá no fundo... [risadas]... depois tem um leão nessa história... UUUAAA! [gesticula o leão]... bem bravo...

Pesquisadora: Bem bravo...

Constança: Bem bravo!

Pesquisadora: Quem é que é bem bravo nessa história?

Constança: [risos] A doença [mantemos a produção sonora instrumental enquanto conversamos].

Paramos de tocar.

Constança: A doença é o pior.

Pesquisadora: Mas me diz uma coisa, [Constança volta a tocar o ganzá enquanto pensa] essa floresta é ser técnica em enfermagem, ou é a UTI?

Constança: É a UTI. [toca o caxixí espaçadamente, depois acelera o andamento] Tu já pensou como é que é isso? Nós funcionamos como os caçadores, os desbravadores, ... criaturas, olha, eu ando até inspirada! [risadas] Eu sou a Chita! [risadas; faz o som de macaca].

Voltamos a tocar e cantar a floresta, com todos os bichos.

Constança: É mais barulhenta.

Pesquisadora: É mais barulhenta ainda?

Constança: É bem barulhenta, tem bastante barulho.

Pesquisadora: Mais?

Constança: Não, tá bom.

...

Constança: É barulhenta: bombas de infusão de hora em hora alarmando...

Pesquisadora: chiiiiiiiii, monitores!

Constança e Pesquisadora: pi,pi,pi,pi,pi,pi,pi,pi, [tocando junto as clavas]... O Dr. Y adora deixar os alarmes ligados, eu detesto, mas fica assim. [Voltamos a tocar as clavas] E ai vem outra bomba... [Imitamos as bombas de infusão] chiiiiiiiiiiiii, chiiiiiiiiiiiii, chiiiiiiiiiiiii, chiiiiiiiiiiii.... São três coisas.... chiiiiiiiiiiii, respirador, bombas, gente falando [Constança imita vozes], telefone tocando [Constança imita o telefone] daqui a pouco toca a campainha... béim!!! [misturamos os sons] chiiiiiiiiiiii, chiiiiiiiiiiii, péin, pein, péin, péin, péin, péin [muita intensidade],

\section{Pesquisadora: piiiiiiiiiiiiiiiiiiiiii}

Constança: Isso ai é apagando fogo! [risadas] É... nossa floresta.

Pesquisadora: E toda ela é assim?

Constança: Nem sempre e nem toda. Tem dias que tá um paraíso [toca as clavas novamente enquanto pensa e conversa]. A gente pode brincar com as crianças, não tem gente chorando ...
As intervenções que utilizaram música dentro da unidade $^{11}$, sobretudo, produziram efeitos importantes. Houve uma clara compreensão de que as profissionais técnicas em enfermagem escolhiam as músicas sempre com a preocupação de conjugarem suas escolhas com os acontecimentos de seu contexto. Constatamos os fortes deslocamentos causados pelo fato dessas trabalhadoras invisibilizadas e julgadas como categoria de "não saber" escolherem músicas para serem colocadas no seu espaço de trabalho, mesmo que escolhessem música "clássica".

Essas intervenções clarificaram também que o andamento (música "lenta") não era um critério tão importante na prática. O elemento musical que realmente tornou-se importante foi a intensidade (volume), pois sua regulagem definia uma música como parte do ruído ou diferenciada dele. Junto a isso se mostrou outra questão, que era a imbricação entre os ruídos e os níveis de tensão de vida e morte e os efeitos "estressantes" sobre as trabalhadoras. Quanto maiores eram as tensões, mais o ruído parecia tornar-se um elemento agregado a essas tensões ${ }^{12}$. Daí que a possibilidade de autonomia e cooperação no uso da música (sobretudo na regulagem da intensidade ${ }^{13}$ ) eram importantes. Eram claras as possibilidades do uso da música como estratégia coletiva de intervenção e desindividualização nos contextos de trabalho - intervenções desestabilizadoras do Panáudio - e da Musicoterapia institucional como abordagem de trabalho e ferramenta para intervenções importantes em Saúde do Trabalhador.

Se os modos de trabalhar da UTI são moldados pelos modos de subjetivação capitalísticos, a música pode permitir que os tempos contidos nas modulações desses fluxos possam ser alterados. Dessa forma, pode desestabilizar os modos de subjetivação em direção à potencialização das práticas de liberdade - aos potenciais de criação, de vida e de sublevação da música enquanto agente produtor de tempos de viver, sentir, pensar, agir e deslocar. O Panáudio parecer ser mais passível de desestabilização que o panóptico, e a música está para muito mais além do que um elemento quase inócuo e bom em qualquer situação, como já referido por inúmeros autores na área da Musicoterapia (Bruscia, 2000; Chagas, 2001b; Ruud, 1990). É necessário operar a desnaturalização do uso da música como "boa para tudo" e, da mesma forma, do que Araújo et al. (2008) chama de "valor positivo universal da música", uma vez que, como prática social, a música também participa de formas de violência existentes nas sociedades. Nem a música por si só poderia produzir a "libertação" do trabalhador ou produzir saúde "naturalmente", nem o relaxamento por si só seria uma alternativa "transformadora" no trabalho, nem à Musicoterapia cabe ocupar apenas os espaços que são atribuídos a ela pelo senso comum. A música, assim, pode ser pensada como 
produtora de efeitos nos modos de subjetivação, de modo a potencializar invenções ou a manutenção das regularidades legitimadas.

Se a música, como aponta Tragtenberg (1999), há muito aprendeu que pode transformar uma mesma cena bucólica e opressiva em nostálgica e futurista, por que esses potenciais não poderiam ser objeto de produção de saúde, de outros modos de trabalhar e mesmo outros modos de existir? A Musicoterapia institucional inspira-se nesses potenciais e busca visibilizar outras contribuições à Musicoterapia bem como ao campo da Saúde.

No que diz respeito ao seu próprio campo, uma dessas contribuições se refere à diferença crucial entre Musicoterapia Institucional, aqui direcionada à Saúde do Trabalhador, e Musicoterapia Organizacional, cujas gêneses e concepções são divergentes e mesmo conflitantes. Há engendramentos e implicações complexos no atendimento a trabalhadores, que é sempre atravessado pelo conflito Capital-Trabalho. Um deles é o histórico processo de responsabilização moral do trabalhador pela doença; outro, o histórico alinhamento da Escola de Recursos Humanos e Psicologia Organizacional com a "resolução de conflitos", "adaptabilidade" do trabalhador e identificação com o empregador, que são áreas que influenciam o trabalho de musicoterapeutas pela via da compreensão "organizacional".

As abordagens direcionadas exclusivamente aos indivíduos não atingem de maneira considerável o coletivo de trabalhadores, de modo a compreender e intervir na melhoria da organização do trabalho, tal como as abordagens voltadas apenas à redução do estresse, uma vez que, no atendimento de Musicoterapia, o trabalhador se refaz, "relaxa", retoma melhores condições físicas e psíquicas e, retornando ao trabalho, é espremido por uma organização do trabalho que não considera seus direitos e necessidades. Dessa maneira, torna-se necessário problematizar as implicações do uso da Musicoterapia sob essas condições (Guazina, 2004), pois se direciona apenas aos efeitos sobre os trabalhadores, sem levar em consideração conflitos de várias ordens (inclusive aqueles decorrentes das configurações contemporâneas do trabalho) que estão presentes nos contextos laborais. Essas são algumas das questões levantadas dentro dessa área, mas que podem ter também ressonâncias dentro da Saúde do Trabalhador e do próprio campo da Saúde, à medida que a Musicoterapia torna-se mais presente nesses diferentes lugares.

\section{Notas}

${ }^{1}$ As "experiências musicais" são compreendidas aqui, a partir de Bruscia (2000), como experiências sonoro-musicais que envolvem as pessoas, bem como o processo, o produto e o contexto em que em que se dão essas interações. Segundo o mesmo autor, as principais experiências musicais são a improvisação musical, a composição, a "re-criação" (utilizar músicas já compostas, no sentido de criar "novamente") e escuta (ou) musical, as quais dão origem às quatro técnicas básicas no campo da Musicoterapia.

${ }^{2}$ A liberdade tem função importante no pensamento foucaultiano e está estreitamente ligada à ética. A ética em Foucault é compreendida como a prática reflexiva da liberdade, e a liberdade, a condição ontológica da ética (Foucault, 2006). A ética é “o tipo de relação que se deve ter consigo mesmo, rapport à soi, ... e que determina a maneira pela qual o indivíduo deve se constituir a si mesmo como um sujeito moral de suas próprias ações" (Foucault, 1995b, p. 263). A moral "é o comportamento efetivo das pessoas" (Foucault, 1995b, p. 265). É na relação consigo, denominada ética, que as grandes mudanças da subjetivação ocorrem. A liberdade é exercida por meio das práticas de liberdade, que são o "exercício de si sobre si mesmo através do qual se procura elaborar, transformar e atingir formas aceitáveis e satisfatórias da existência ou da sociedade política definida pelo próprio povo, sociedade ou indivíduos" (Foucault, 2006, p. 265).

${ }^{3}$ Em que pesem o histórico processo de responsabilização moral do trabalhador pela doença, o histórico alinhamento da Escola de Recursos Humanos e Psicologia Organizacional com a "adaptabilidade" do trabalhador e identificação com o empregador. Elementos que, portanto, também estarão presentes na prática musicoterápica pautada nessas concepções.

${ }^{4}$ As práticas divisórias são aquelas que, para Foucault (1995a), objetivam o sujeito a partir de separações que se dão no interior do sujeito e em relação aos outros, em um processo que o objetiva, "categoriza o indivíduo, marca-o por sua própria individualidade, liga-o à sua própria identidade, impõe-lhe uma lei de verdade, que devemos reconhecer e que os outros têm de reconhecer nele" (p. 235).

${ }^{5}$ Referiremos à categoria sempre no gênero feminino porque todas as técnicas em enfermagem participantes eram mulheres. Note-se que a ampla maioria desta categoria tem seus postos de trabalho ocupados por mulheres ou, de outro modo, é uma atividade comumente associada ao feminino.

${ }^{6}$ Como o trabalho em turnos, a hierarquia rígida, a presença de agentes patogênicos no espaço laboral, a convivência com a morte dos doentes e a desqualificação social comumente atribuída às tarefas de cuidar, alimentar e limpar, entre outras.

${ }^{7}$ Paisagem Sonora: conceito cunhado pelo compositor canadense Murray Schafer (anos 60), como parte do Word Soudscape Project, movimento que se propunha analisar o ambiente acústico como um todo. Soudscape é um neologismo da palavra landscape (paisagem) e significa o ambiente sonoro, ou seja, uma porção do ambiente sonoro vista como um campo de estudos (Schafer, 2001).

${ }^{8}$ Para Schafer (1991), "ruído é o som indesejável", mais do que um som de altura não determinada.

${ }^{9}$ Esta pesquisa teve como base a pesquisa-intervenção (Rocha \& Aguiar, 2003) onde a relação pesquisador/objeto pesquisado é dinâmica e determina os próprios caminhos da pesquisa, concebida como sendo uma produção do grupo envolvido. Com base nessa referência, esta pesquisa produziu-se em quatro fases. A primeira caracterizou-se pela observação participante realizada dentro da UTI Pediátrica, onde o mapeamento da paisagem sonora da unidade e as conversas com as trabalhadoras foram cruciais. Em uma segunda fase foram propostas oficinas de Musicoterapia, em que foram 
utilizadas diferentes técnicas musicoterápicas (Bruscia, 2000) como Escuta Musical, Re-criação musical - caracterizada pela execução de músicas já conhecidas-, Composição e Improvisação musical. Uma terceira fase foi o retorno ao espaço da UTI Pediátrica para gravação da paisagem sonora e posterior discussão com um grupo de profissionais técnicas em enfermagem da unidade. Por fim, como efeito dos processos anteriores e frente à sugestão das profissionais sobre o uso de música na unidade como uma estratégia possível de melhora do contexto de trabalho, procedemos à última fase do campo, que foi a intervenção musical dentro da unidade, onde as trabalhadoras participaram na escolha e regulagem das músicas utilizadas na UTI. A descrição de todo este campo encontra-se na dissertação que gerou este artigo.

${ }^{10} \mathrm{O}$ hospital está associado a muitas discursividades de silêncio: a figura de enfermeira disciplinadora com dedo em riste em frente aos lábios, as placas de trânsito que ordenam silêncio, as ordens hierárquicas que ordenam silêncio. Entretanto, o silêncio (enquanto percepção, e não silêncio absoluto) contrasta com os sons dos fluxos: sons de aparelhos, sons de pessoas que transitam, que conversam, que choram, ruídos das mais diferentes origens, avisos sonoros das mais diversas naturezas.

${ }^{11}$ Neste caso específico, tratamos das intervenções em que utilizamos a técnica musicoterápica de Escuta Musical (Bruscia, 2000) e que, nesta proposta, eram escolhidas, sobretudo, pelas profissionais técnicas em enfermagem. Essa técnica, neste momento, foi utilizada com o objetivo de possibilitar a intervenção das trabalhadoras sobre seu contexto de trabalho, conforme preceitos da Saúde do Trabalhador, porém, com a mediação da musicoterapeuta pesquisadora. Algumas músicas também foram escolhidas pela pesquisadora, com base no processo de pesquisa e premissas de intervenção em Musicoterapia, bem como foram observados os efeitos das músicas sobre os demais sujeitos presentes em cada local da unidade em que era feita a intervenção. Para maiores detalhes, recorrer à dissertação que embasa este artigo.

${ }^{12}$ Esses são efeitos diferenciados do desgaste provocado pelos limiares extremos de som apontados pelo Ministério do Trabalho.

${ }^{13}$ Coloquialmente referido como "volume".

\section{Referências bibliográficas}

Araújo, S. (1992-1993). Descolonização e discurso: notas acerca do poder, do tempo e da noção de música. Revista Brasileira de Música, 20, 25 - 31.

Araújo, S., Araújo, D., Nascimento, G., Alves, I., Salustriano, H., Faustino, N. et al. (2006). A violência como conceito na pesquisa musical: reflexões sobre uma experiência dialógica na Maré, Rio de Janeiro. Revista Transcultural de Música. Acesso em fevereiro, 2008, em http://www.sibetrans.com/ trans/trans10/araujo.htm

Bruscia, K. (2000). Definindo musicoterapia. (M. V. F. Conde, Trad.). Rio de Janeiro: Enelivros.

Canguilhem, G. (2002). O normal e o patológico (M. T. R. C. Barrocas \& L. O. F. B. Leite, Trads., $5^{\text {a }}$ ed.). Rio de Janeiro: Forense Universitária. (Original publicado em 1966).

Castel, R. (1998). As metamorfoses na questão social: uma crônica do salário (I. D. Poleti, Trad.). Petrópolis, RJ: Vozes. (Original publicado em 1995).
Chagas, M. (2001a). Musicoterapia: desafios da interdisciplinaridade entre a modernidade e a contemporaneidade. Dissertação de Mestrado, Programa de Pós-graduação em Psicossociologia de Comunidades e Ecologia Social, Universidade Federal do Rio de Janeiro.

Chagas, M. (2001b). Saúde e pesquisa ressonâncias na história. In Associação de Musicoterapia do Paraná (Org.), Anais do III Fórum Paranaense de Musicoterapia, Encontro Paranaense de Musicoterapia e II Encontro Nacional de Pesquisa em Musicoterapia (pp. 56-61). Curitiba: AMT-PR.

Costa, C. M. (1989). O despertar para o outro: musicoterapia. São Paulo: Sumus.

Deleuze, G. (1992). Sobre as sociedades de controle. In G. Deleuze, Conversações (pp. 219-226). Rio de Janeiro: Ed. 34.

Dias, E. (1994). A atenção à saúde dos trabalhadores no setor saúde (SUS) no Brasil: realidades, fantasias ou utopia. Tese de Doutorado, Programa de Pós-graduação em Saúde Coletiva, Universidade Estadual de Campinas.

Durand, J. P. (2003). A refundação do trabalho no fluxo tensionado. Tempo Social, 15(1), 139-158.

Foucault, M. (1975). Vigiar e punir (R. Ramalhete, Trad.). Petrópolis, RJ: Vozes.

Foucault, M. (1995a). O sujeito e o poder. In H. Dreyfus \& P. Habinow, Michel Foucault: uma trajetória filosófica para além do estruturalismo e da hermenêutica (pp. 231-249). Rio de Janeiro: Forense Universitária.

Foucault, M. (1995b). Michel Foucault entrevistado por Hubert L. Dreyfus e Paul Rabinow. In H. Dreyfus \& P. Rabinow, Michel Foucault: uma trajetória filosófica para além do estruturalismo e da hermenêutica (pp. 253 - 278). Rio de Janeiro: Forense Universitária.

Foucault, M. (2003a). Verdade e poder. In R. Machado (Org. e Trad.), Microfísica do poder (18 a ed., pp. 1-14). Rio de Janeiro: Graal. (Original publicado em 1979).

Foucault, M. (2003b). A ordem do discurso (L. F. A. Sampaio, Trad., $9^{\text {a }}$ ed.). São Paulo: Ed. Loyola. (Original publicado em 1971).

Foucalt, M. (2006). A ética do cuidado de si como prática da liberdade. In M. B. da Motta (Org.), Ditos e escritos: Vol. 5. Ética, sexualidade, politica (E. Monteiro \& A. D. Barbosa, Trads., $2^{\text {a }}$ ed., pp. 264-287). Rio de Janeiro: Forense Universitária.

Gaston, E. T. (1968). Tratado de musicoterapia. Buenos Aires: Paidós.

Guazina, L. (2004). Musicoterapia e cuidado: ressonâncias no campo da saúde mental e trabalho [CD-ROM]. In Associação de Musicoterapia do Rio de Janeiro (Org.), Anais do V Encontro Nacional de Pesquisa em Musicoterapia. Rio de Janeiro: AMT-RJ

Lapoujade, C. \& Lecourt, E. (1996). A pesquisa francesa em musicoterapia. Revista Brasileira de Musicoterapia, 1, Acesso em fevereiro, 2008, em http://www.ubam.hpg.com.br/html/ docs/rbm01_2.htm.

Lopes, M. J. M. \& Leal, S. M. C. (2005). A feminização persistente na qualificação profissional da enfermagem brasileira. Cadernos Pagu, 24, 05-25.

Napolitano, M. (2002). História e música. Belo Horizonte: Autêntica.

Nardi, H. C. (1999). Saúde, trabalho e discurso médico: a relação médico-paciente e o conflito capital-trabalho. São Leopoldo: Ed. da UNISINOS.

Nardi, H. C. (2003). Ética, trabalho e subjetividade: trajetórias de vida e processos de subjetivação na virada do século. Tese de Doutorado, Universidade Federal do Rio Grande do Sul. 
Nardi, H. C., Tittoni, J., \& Bernardes, J. S. (2002). Subjetividade e trabalho. In A. D. Cattani (Org.), Dicionário crítico sobre trabalho e tecnologia ( $4^{\mathrm{a}}$ ed., pp. 302-308). Petrópolis, RJ: Vozes/ Porto Alegre: Ed. UFRGS.

Osório da Silva, C. (2002). Vida de hospital: a produção de uma metodologia para o desenvolvimento da saúde do profissional de saúde. Tese de Doutorado, Fundação Oswaldo Cruz, Escola Nacional de Saúde Pública, Rio de Janeiro.

Pitta, A. (1999). Hospital: dor e morte como oficio ( $3^{\mathrm{a}}$ ed.). São Paulo: Hucitec.

Rocha, M. \& Aguiar, K. (2003). Pesquisa-intervenção e a produção de novas análises. Psicologia, Ciência e Profissão, 23(4), 64-73.

Ruud, E. (1990). Caminhos da musicoterapia. São Paulo: Summus.

Schafer, M. (1991). O ouvido pensante. São Paulo: UNESP.

Schafer, M. (2001). A afinação do mundo. São Paulo: UNESP.

Tittoni, J. (2002). Saúde mental. In A. D. Cattani (Org.), Dicionário crítico sobre trabalho e tecnologia ( $4^{\mathrm{a}}$ ed., pp. 279-283). Petrópolis, RJ: Vozes/ Porto Alegre: Ed. UFRGS.

Tittoni, J. (2004). Saúde mental, trabalho e outras reflexões sobre a economia solidária. In A. Merlo (Org.), Saúde e trabalho no Rio Grande do Sul: realidade, pesquisa e intervenção (pp. 65-93). Porto Alegre: Ed. UFRGS.

Tragtenberg, L. (1999). Música de cena. São Paulo: Perspectiva. Wisnik, J. (2001). O som e o sentido: uma outra história das músicas. São Paulo: Companhia das Letras.

Laize Guazina é Musicista e musicoterapeuta, Mestre em Psicologia Social e Institucional (UFRGS) e doutoranda do Programa de Pós-graduação em Música da UNIRIO. Professora da graduação em Musicoterapia da Faculdade de Artes do Paraná (FAP). Endereço para correspondência: FAP - Rua dos Funcionários 1357. Cabral. Curitiba - PR. Endereço eletrônico: laizeg@ig.com.br

Jaqueline Tittoni é doutora em Sociologia pela UFRGS e realizou pós-doutorado junto ao Doutorado em Psicologia

Social na Universidade Autônoma de Barcelona. Atualmente é professor adjunto da Universidade Federal do Rio Grande do Sul, tutor do grupo PET - Psicologia. Sua produção situa-se na área de Psicologia, com ênfase em Fatores Humanos no Trabalho e nos seguintes temas: trabalho, subjetivação, saúde mental, subjetividade e psicologia social. Endereço eletrônico: jaquemin@terra.com.br

\author{
Musicoterapia institucional na saúde do trabalhador: \\ conexões, interfaces e produções \\ Laize Guazina e Jaqueline Tittoni \\ Recebido: 05/11/2007 \\ $1^{\text {a }}$. Revisão: $10 / 04 / 2008$ \\ $2^{\text {a }}$. Revisão: $19 / 06 / 2008$ \\ Aceite final: 23/06/2008
}

